\title{
Daya Dukung Silvopastur di Kecamatan Insana Kabupaten Timor Tengah Utara Nusa Tenggara Timur
}

\author{
Silvopastur Carrying Capacity of In Sub District of North Timor Taraah District Nusa Tenggara Timur \\ I. Naikofi ${ }^{1}$, N. Wijayanto ${ }^{1}$, \& A. M. Fuah ${ }^{1}$ \\ ${ }^{1}$ Departemen Ilmu Produksi dan Teknologi Peternakan, Fakultas Peternakan, IPB \\ Jalan Agatis, Kampus IPB Dramaga, Bogor 16680, Indonesia \\ Email koresponden author: kristina.naikofi@gmail.com
}

\begin{abstract}
Research on "Carrying capacity of silvopastur in Insana Subdistrict, North Central Timor Regency, East Nusa Tenggara" has been carried out from April to June 2018. This study aims to identify the types and availability of animal feed to analyze the strategy of developing cattle basel carrying capacity of silvopastur in Insana Regency. This research was conducted using survei method on secondary data collection. The analysis used was descriptive analysis and SWOT analysis. The results showed that (1) the types of forages found in three villages are: grass includes; alang-alang grass (Imperata cylindrica), field grass (Axonopus compressus) (b) leguminosa consisting of shy daughters (Mimosa pudica), and feed from food crops in the form of rice straw, corn straw, sweet potatoes, banana stems. (c) and several types of forages from forestry plants in the form of how manikin (Bauhinia purpurea), Kabesak (Vachellia leucophloea). (2) The highest potential area for developing ruminants is Manunain B village as much as 800999.84 animal unit, with an increasing population capacity of $18.53 \%$, and followed by Tapenpah Village with 457358.94 animal unit with an increase capacity by $51.12 \%$, while Sekon Village is still can accommodate 423501.18 animal unit with an increase capacity of $30.33 \%$.
\end{abstract}

Keywords: Carrying capacity, silvopastur, SWOT

\section{PENDAHULUAN}

Nusa Tenggara Timur (NTT) merupakan salah satu Provinsi yang dijuluki sebagai gudang ternak (Sukada et al. 2016) termasuk Kabupaten Timor Tengah Utara. Kabupaten Timur Tengah Utara terletak di Pulau Timor bagian barat yang memiliki potensi untuk pengembangan usaha ternak memiliki padang savana yang luas sekitar 167637 ha atau sekitar $62,79 \%$ karena luas wilayah kabupaten Timor Tengah Utara (BPS Kabupaten TTU 2018).

Kecamatan Insana merupakan salah satu Kecamatan yang memiliki luas wilayah paling besar di Kabupaten TTU dengan luas 330,08 ha atau $12,48 \%$ dengan dasar hukum Keputusan Gubernur No. 66/1/33 tahun 1962. Selain itu Kecamatan Insana memiliki potensi untuk pengembangan ternak yang cukup besar, kuantitas peternakan di daerah tersebut meliputi peternakan sapi, kerbau, kuda, kambing. Hasil budidaya ternak sapi di Kecamatan Insana yaitu populasinya sekitar 11542 ekor (BPS Kabupaten TTU 2018).

Sistem pemeliharaan ternak sapi yang diterapkan di Kecamatan Insana sebagian besar masih sangat tradisional sehingga dalam pemberian pakan juga tidak secara intensif (Manu 2013) di mana ternaknya dapat digembalakan pada siang hari dan dikandangkan pada malam hari (Parakkasi 1999; Suryana 2009; Rangkuti dan Siregar 1997; Liem et al. 2000).

Masyarakat Kecamatan Insana lebih memilih manajemen ternak pola penggembalaan atau secara semi intensif dengan alasan peternak dapat memelihara ternak dalam jumlah yang lebih banyak dibanding dengan pemeliharaan intensif (Priyanto dan Yulistianu 2005). Sistem intensif juga diterapkan masyarakat Uganda (Wurzinger et al. 2009; Mbabazi dan Ahmed 2012) kerana sangat efisien dalam penggunaan tenaga kerja karena tidak perlu mencari pakan, ternak dilepas dilahan pada periode tertentu dan ternak bebas memilih hijauan untuk memacu produktivitas ternak dengan pola digembalakan.

Pemeliharaan pola intensif hanya berlaku pada sapi jantan, ternak dikandangkan atau diikat di bawah pohon selama masa pemeliharaan dan peternak mencari dan memberikan pakan dan air pada ternaknya (cut and carry). Pakan yang diberikan pada ternak adalah hijauan rumput alam di padang pengembalaan, rumput raja (Setiana 2000; Salendu dan Elly 2012), selain itu ternak mendapat pakan dari limbah pertanian, tanaman pangan serta hijauan dan pohon di areal hutan.

Silvopastur merupakan gabungan antara ternak, pakan ternak dan pohon pada satu unit lahan yang sama 
(Lindgren dan Sullivan 2013). Silvopastur memberikan manfaat ekonomi dan lingkungan kepada masyarakat (Donaghy et al. 2010; Clason 1995; Zinkhan dan Mercer 1997). Selain itu silvopastur memberikan manfaat sebagai tempat penyerapan karbon (Leu 2005; Steinfel et al. 2006; Baah-Acheamfour et al. 2015), penahan erosi tanah (Clason dan Sharrow 2000; Mills et al. 2006), biodiversitas (Karki et al. 2013), memberikan nutrisi bagi tanaman dan meningkatkan aktivitas mikroba tanah (Bardgett et al. 1998; Wardle et al. 2004; Maharning et al. 2009). Dalam sistem silvopastur terdapat pakan ternak yang produksinya di pengaruhi oleh cahaya, nutrisi hara, jenis vegetasi dan kerapatan (Burner dan Brauer 2003; Classon 1999; Dube et al. 2012; Feldhake et al. 2005; Debruyne et al. 2001; Jewell et al. 2007; Lonati et al. 2015).

Pengembangan sistem silvopastur sangat di pengaruhi oleh luas wilayah (Mukson et al. 2008) dan daya dukung pakan ternak yang baik (Sumarjono et al. 2008), Daya dukung pakan merupakan kemampuan suatu wilayah pastura untuk menghasilkan, menyediakan makanan, serta menampung berapa banyak jumlah ternak ruminansia tanpa melalui pengolahan, sehingga kebutuhan hijauan rumput terpenuhi dengan cukup dalam satu tahun (Rinaldi et al. 2012; Rusnan et al. 2015). Masyarakat masih kurang paham dengan adanya daya dukung peternakan dapat meningkatkan pendapatan dan kesejahteraan masyarakat (Haile et al. 2011; Mandaka et al. 2005; Mukson et al. 2009; Suryanto 1993). Berdasarkan permasalahan di atas, dilakukan penelitian yang bertujuan mengidentifikasi jenis dan menganalisis ketersediaan pakan ternak atau HMT, menganalisis daya dukung silvopastur terhadap ternak sapi dan merumuskan strategi pengembangan ternak sapi di Kecamatan Insana.

\section{METODE}

\section{Tempat Penelitian}

Penelitian ini dilaksanakan di Kecamatan Insana, Kabupaten Timor Tengah Utara, Nusa Tenggara Timur. Data dikumpulkan menggunakan metode survei dan pengamatan langsung pada desa yang dipilih secara sengaja (purposive sampling), yaitu desa yang mimiliki jumlah ternak dan HMT tertinggi, terendah dan sedang. Penentuan responden dilakukan secara sengaja terhadap peternak yang mengelola silvopastura dan memiliki ternak, di Kecamatan Insana. Lokasi penelitian di tiga desa yaitu Desa Sekon, Tapenpah, dan Manunain B.

Data yang diperoleh data hijauan tanaman pohon yang dikumpulkan adalah berupa jenis pohon dan jumlah individu perjenis untuk di hitung indeks nilai penting. Data yang diperoleh dianalisis dengan menghitung:indeks nilai penting dan indeks keanekaragaman dan daya dukung terhadap ternak ruminansia (khusus sapi potong). Penentuan strategi pengembangan peternakan sapi potong menggunakan analisis SWOT yakni melalui tahapantahapan IFE (internal factor evaluation) dan EFE (external factor evaluation) untuk menganalisis faktor-faktor internal dan eksternal. Analisis posisi strategis disajikan menggunakan matriks IE (internal external). Setelah diketahui posisi strategis maka dapat dirumuskan beberapa strategi alternatif menggunakan matriks SWOT.

\section{HASIL DAN PEMBAHASAN}

\section{Identifikasi Jenis dan Analisis Ketersediaan Pakan Ternak Sapi Potong}

Hasil identifikasi dan analisis HMT menunjukkan bahwa kualitas hijauan yang dikonsumsi ternak sapi pada lokasi penelitian sudah cukup memadai terdiri dari berbagai jenis leguminosa rumput-rumputan dan pepohonan yang daunnya disukai dan dapat dikonsumsi ternak Selain itu, ketersediaan hijauan yang bervariasi cukup besar dengan komposisi botani yaitu terdiri dari jenis pakan berupa (a) rumput meliputi rumput alang-alang (Imperata cylindrica), rumput lapang (Axonopus compressus); (b) leguminosa terdiri dari putri malu (Mimosa pudica) dan pakan dari tanaman pangan terdiri dari jerami padi, jerami jagung, ubi jalar, batang pisang; (c) dan ada beberapa jenis HMT dari tanaman kehutanan berupa hau maninikin (Bauhinia purpurea), kabesak (Vachellia leucophloea). Dari hasil pengamatan vegetasi tumbuhan yang dilakukan wilayah Insana memiliki keanekaragaman jenis tumbuhan yang bervariasi yaitu dengan menghitung indeks nilai penting dan indeks keanekaragaman.

\section{Indeks Nilai Penting}

Jenis tumbuhan yang memiliki nilai Indeks Nilai Penting (INP) tertinggi merupakan jenis dominan. INP merupakan parameter dominansi suatu jenis dalam komunitas tumbuhan. Jenis tumbuhan yang memiliki INP tinggi memiliki peran penting dalam suatu kawasan (Sundarapan dian dan Swamy (2000) sebab INP merupakan penjumlahan dari kerapatan relatif (KR), frekuensi relatif (FR), dan dominansi relatif (DR) (Soerianegara dan Indrawan 2005). Indriyanto (2008) menyatakan bahwa besarnya nilai INP menandakan besar atau tidaknya pengaruh jenis tersebut dalam suatu komunitas tumbuhan. Penguasaan spesies tertentu dalam suatu komunitas apabila spesies yang bersangkutan berhasil menempatkan sebagian besar sumber daya yang ada dibandingkan dengan spesies yang lainnya (Saharjo dan Cornelia 2011).

Keanekaragaman hayati di tiga Desa yakni Desa Tapenpah, Desa Manunain B dan Desa Sekon dapat diidentifikasi berdasarkan data yang diperoleh. Jika dilihat dari jumlah dan jenis pohon pada ketiga silvopastur memiliki jenis yang relatif sama yaitu pada Desa Manunain B terdapat 46 jumlah pohon dari 4 jenis pohon. di Desa Sekon terdapat 41 jumlah pohon dari 3 jenis pohon. dan Desa Tapenpah terdapat 39 jumlah pohon dari 7 jenis pohon. Ada 3 jenis pohon yang ditemui di tiga desa tersebut yaitu pohon Asam (Tamarindus indica), pohon Hu'ak (Eucalyptus alba) dan pohon Kom (Zizipthus mauritiania), yang mendominasi oleh pohon Hu'ak.

Jika dibandingkan antara silvopastur Desa Tapenpah, Manunain B, dan Sekon. Desa Sekon memiliki INP tertinggi 237.04 pada tingkat pada Pohon Eucalyptus alba dengan hal ini didukung oleh penelitian Sutisna (2005) dalam Irwanto (2006) bahwa masing-masing INP lebih tinggi dari 15\% dan lebih dari $10 \%$ pada permudaan alam. Untuk perbandingan INP tertinggi antara Desa Tapenpah. Manunain B dan Sekon dapat dilihat pada Gambar 1. 


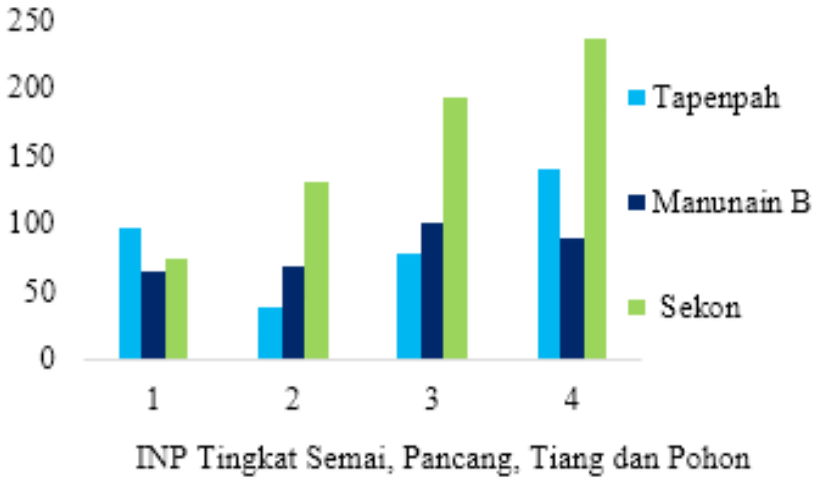

Gambar 1. Perbandingan INP Tertinggi antara Desa Tapenpah, Manunain B, dan Sekon

\section{Indeks Keanekaragaman}

Tingkat keanekaragaman jenis tumbuhan dapat diketahui melalui nilai H' (Arrijani 2008). Indeks keanekaragaman spesies merupakan informasi penting bagi komunitas tumbuhan. Indeks keanekaragaman jenis ditentukan oleh dua hal. yaitu kekayaan jenis dan kemerataan jenisnya. Kestabilan ini dipengaruhi oleh banyaknya jumlah individu yang ditemukan, jumlah seluruh jenis. dan kemerataan komunitas tumbuhannya. Keanekaragaman jenis tingkat tiang dan pohon pada masing-masing lokasi penelitian bervariasi.

Gambar 2 menunjukkan bahwa perbedaan nilai indeks keanekaragaman jenis (H') tingkat tiang pada setiap lokasi penelitian tidak terlalu jauh dengan nilai H' tertinggi pada Manunain B yaitu 3,68. Keanekaragaman jenis tingkat tiang pada tiga lokasi penelitian termasuk dalam tingkatan keanekaraman tinggi dengan nilai $H^{\prime}>3$. hal ini sesuai dengan pernyataan Barbour (1987), bahwa suatu komunitas indeks keanekaragaman jenis sebesar 3,2917 termasuk dalam kategori tinggi. Semakin tinggi nilai keanekaragaman suatu kawasan menunjukkan semakin stabil komunitas di kawasan tersebut (Wiraksumah 2003). Vegetasi yang sama dapat memberikan manfaat seperti naungan dan peningkatan kualitas udara (Donavan dan Butry, 2009; Escobedo dan Nowak, 2009; Mcpherson et a.l 1997; Noewek et al. 2000).

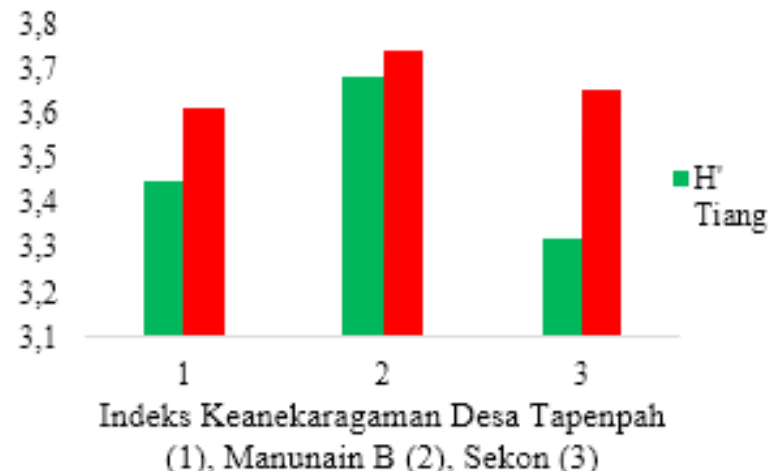

Gambar 2. Indeks Keanekaragaman Desa Tapenpah, Manunain B, dan Sekon

\section{Daya Dukung Hijauan Makanan Ternak Berdasarkan Bahan Kering (BK)}

Indeks daya dukung (IDD) hijauan makanan ternak dihitung dari jumlah produksi hijauan makanan ternak yang tersdia terhadap jumlah kebutuhan hijauan bagi sejumlah populasi ternak ruminansia di suatu wilayah. Indeks daya dukung mencerminkan tingkat keamanan pakan pada suatu wilayah, untuk mendukung kehidupan ternak yang berada diwilayah tersebut. Hasil analisis daya dukung hijauan makanan ternak berdasarkan bahan kering (BK) pada lokasi penelitian.

Data pada Tabel 1 menunjukkan bahwa Desa Manunain B lebih potensial dan dikembangkan prioritas utama yang mampu menampung jumlah ternak sapi sebanyak 800 999,84 ST, dengan kapasitas peningkatan populasi sebesar $18,53 \%$. Prioritas kedua adalah Desa Tapenpah yang menempati dengan jumlah 457 58,94 ST dengan kapasitas peningkatan $51,12 \%$, sedangkan Desa Sekon masih dapat menampung sebesar 423 501,18 ST dengan kapasitas peningkatan 30,33\%. Berdasarkan hasil yang diperoleh dibuat analisis SWOT dan strategi yang ditetapkan dalam bentuk matriks pada Tabel 2 untuk pengembangan ternak sapi di Kecamatan Insana.

Tabel 1. Kebutuhan pakan untuk setiap satuan ternak (ST) adalah 9,1 kg BK/hari (Ashari et al. 1999)

\begin{tabular}{lccccc}
\hline Desa & $\begin{array}{c}\text { Bahan Kering } \\
(\text { TON })\end{array}$ & $\begin{array}{c}\text { Daya Dukung } \\
(\text { ST })\end{array}$ & $\begin{array}{c}\text { Populasi saat ini } \\
(\text { ST })\end{array}$ & $\begin{array}{c}\text { Potensi pengembangan } \\
(\text { ST })\end{array}$ & $\begin{array}{c}\text { Kapasitas peningkatan } \\
(\%)\end{array}$ \\
\hline Tapenpah & 364197,28 & 33141,95 & 1200 & 457358,94 & 51,12 \\
Manunain B & 304014,84 & 14731,03 & 435 & 800999,84 & 18,53 \\
Sekon & 161171,02 & 27665,35 & 712 & 423501,18 & 30,33 \\
Total & 829383,14 & 75538,33 & 2347 & 1681859,96 & 100 \\
\hline
\end{tabular}


Tabel 2. Matriks SWOT dan strategi pengembangan sapi di Kecamatan Insana

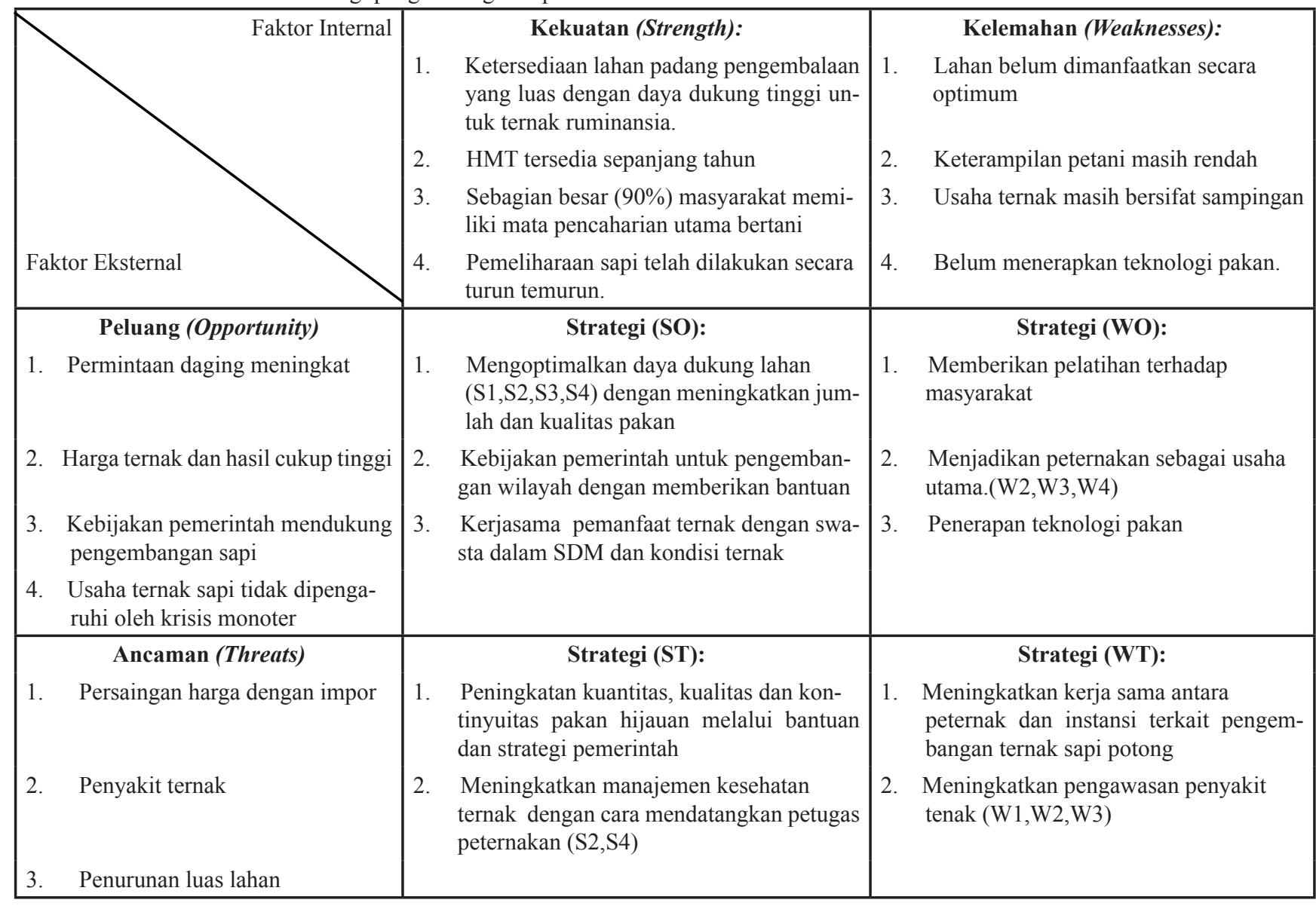

\section{KESIMPULAN}

Jenis HMT yang di temukan di wilayah Kecamatan pada tiga desa yaitu: (a) rumput meliputi; rumput alangalang (Imperata cylindrica), rumput lapang (Axonopus compressus) (b) leguminosa terdiri dari putri mali (Mimosa pudica), dan pakan dari tanaman pangan terdiri dari jerami padi, jerami jagung, ubi jalar, batang pisang. (c) dan ada beberapa jenis HMT dari tanaman kehutanan berupa hau maninikin (Bauhinia purpurea), kabesak (Vachellia leucophloea). Desa yang paling potensial dalam penyediaan pakan serta untuk pengembangan ternak ruminansia adalah Desa Manunain B dengan jumlah ternak sapi sebanyak 800 99984 ST, dengan kapasitas peningkatan populasi sebesar $18,53 \%$. Optimalisasi daya dukung lahan menjadi strategi utama dengan cara penyiapan pakan yang cukup untuk meningkatkan daya dukung ternak. Prioritas kedua dengan cara kerjasama dengan instansi cabang dinas peternakan untuk meningkatkan sumber daya manusia dan kapasitas budidaya ternak dan pakan.

\section{DAFTAR PUSTAKA}

Baah-Acheamfour M., S. X. Chang, C. N. Carlyle, \& E. W. Bork. 2015. Carbon pool size and stability are affected by trees and grassland cover types within agroforestry systems of western Canada. Agriculture Ecosystems \& Environment. 2(13):105-113.

Bardgett, R. D., D. A. Wardle, \& G. W. Yeates. 1998. Plant growth and soil microbial community structure of legumes and grasses grown in monoculture or mixture. Science Direct. 20(10):1231-1237

Burner, D. M., \& D.K.Brauer. 2003 Herbage response to spacing of loblolly pine trees in a minimal management silvopasture in southeastern USA. Agroforestry Systems. 57(1):69-77

BPS Kabupaten TTU [Badan Pusat Statistik Kabupaten Timut Tengah Utara]. 2018. Timor Tengah Utara dalam Angka. Kefamenanu: Timor Tengah Utara.

Clason, T. R., \& S. H. Sharrow. 2000. Silvopasture practices. In North American agroforestry: An integrated science and practice. WI: American Society of Agronomy. 119-147.

Donovan, G. H., \& D. T. Butry. 2009. The value of shade: Estimating the effect of urban trees on summertime electricity use. Energy and Buildings. 41(6):662-668.

Donaghy, P., S. Bray, G. Rebecca, J. Rolfe, M. Stepens, M. Hoffman, \& A. Stunzer. 2010. The bioeconomic 
potential for agroforestry in Australia's northern grazing systems. Small-scale Forestry. 9:463-484.

Dube, F., M. Espinosa, N. Stolpe, E. Zagal, NV. Thevathasan, \& A.M. Gordon. 2012. Productivity and carbon storage in silvopastoral systems with Pinus ponderosa and Trifolium spp. plantations and pasture on an Andisol in Patagonia. Chile. Agrofor Syst. 86(2):113-128.

Feldhake, C. M., J.P.S Neel, D. Belesky, \& E.L. Mathias. Light Measurement Methods Related to Forage Yield in a Grazed Northern Conifer Silvopasture in the Appalachian Region of Eastern USA. Agroforestry Systems. 65(3):231-239

Houx, J. H., R. I. McGraw, H. E. Garret, R. I. Kalllebach, F. B. Fritschi, \& W. Rogers. 2012. Exent of vegetationfree zona necessary for silvopasture establishment of eastem black walnut seedlings in tall fescue. Agroforestry systems. 87:73-80.

Escobedo, F. J. \& D. J. Nowak. 2009. Spatial heterogeneity and air pollution removal by an urban forest. Landscape and Urban Planning. 90:102-110.

Irwanto. 2006. Pengaruh perbedaan naungan terhadap pertumbuhan semai Shorea sp. di persemaian. Tesis. Sekolah Pascasarjana, Institut Pertanian Bogor, Bogor.

Karki, S., G. Rizal, \& W. P. Quick. 2013. Improvement of photosynthesis in rice (Oryza sativa L.) by inserting the C4 pathway. Rice. 6:1-8

Leu, S. 2005. Diryland Agroforestry for Biomass. Carbon Seguestration and Desert Rehabilitation. In: Proceedings of the 14th European Biomass Conference. Paris. pp. 341-344.

Liem, C. H. H., A. Marawali, A. Kedang, R. B. Bamualim, W. Yusuf, \& J. Nulik. 2000. Analisis Pemasaran Ternak Sapi Potong di Nusa Tenggara. AKP. 2(4): 356-370.

Lindgren, P. M. F. \& T. P. Sullivan. 2013. Response of forage yield and quality to thinning and fertilization of young forests: implications for silvopasture management. Canadian Journal of Forest Research. 44:281-289.

Maharning, A. R., A. A. S. Mills, \& S. M. Adl. 2009. Soil community changes during secondary succession to naturalized grasslands. Applied Soil Ecology. 41(2):137-147.

Mills, R. E., C. T. Luttig, C. E. Lzrkins, A. Beauchamp, C. Tsui, W. S. Pittard, \& S. E. Devine. 2006. An initial map of insertion and deletion (INDEL) variation in the human genome. Genome Res. 16(9):1182-1190.

Rangkuti, F., \& C. Siregar. 1997. Analisis SWOT: teknik membedah kasus bisnis. PT. Gramedia Pustaka Utama, Jakarta.

Salendu, A. H. S. \& F. H. Elly. 2012. Pemanfaatan lahan di bawah pohon kelapa untuk hijauan pakan sapi di Sulawesi Utara. Trop Anim Health Prod. 45(6):13691374.
Setiana, M. G. 2010. Pengenalan jenis hijauan makanan ternak unggul. Depertemen ilmu nutrisi dan makanan ternak. Tesis. Fakultas Peternakan. Bogor. Institut Pertanian Bogor.1-24

Steinfeld, H., P. Gerber, T. Wassenaar, V. Castel, M. Rosales, M., \& C. de Haan. 2006. Livestock's long shadow. FAO, Rome.

Sukada, I. K., I. W. Subrata, \& I. G. Suarta. 2016. Potensi Ternak Sapi Potong. Sapi Perah dan Kerbau Sebagai Penghasil Daging di Kabupaten Nusa Tenggara Timur. Majalah Ilmiah Peternakan. 19(3).

Suryana. 2009. Pengembangan Usaha Ternak Sapi Potong Berorientasi Agribisnis dengan Pola Kemitraan. Jurnal Litbang Pertanian. 28(1):29-37.

Sutisna, M. 2005. Silvikultur Hutan Alam Di Indonesia Fakultas Kehutanan, Universitas Mulawarman, Samarinda.

Syamsu, A. J., L. A. Sofyan, K. Mudikdjo, \& G. Said. 2003. Daya dukung limbah pertanian sebagai sumber pakan ternak ruminansia di Indonesia. Wartazoa. 13(1):30-37.

Suryana. 2009. Pengembangan Usaha Ternak Sapi Potong Berorientasi Agribisnis dengan Pola Kemitraan. Jurnal Litbang Pertanian. 28(1):29-37.

Manu, A. E. 2013. Produktivitas padang penggembalaan sabana Timor Barat. J Pastura. 3(1):25-29.

Mbabazi, M. C. \& M. Ahmed. 2012. Analysis of incentives and disincentives for beef in Uganda, Technical notes series, MAFAP. FAO, Roma.

McPherson, E. G., Nowak, D. Heisler, G. Grimmond, S. Souch, C. Grant, \& R. Rowntree. 1997. Quantifying urban forest structure, function, and value: The Chicago Urban Forest Climate Project. Urban Ecosystems 1:4961.

Nowak, D. J., K. L. Civerolo, T. Rao, S. Sistla, G. Luley, \& E. D. Crane. 2000. A modeling study of the impact of urban trees on ozone. Atmospheric Environment. 34:1601-1613.

Parakkasi, A. 1999. Ilmu Gizi dan Makanan Ternak Monogastrik. Penerbit Angkasa, Bandung.

Priyanto, M. D. \& D. Yulistiani. 2005. karakteristik Peternak Domba/ Kambing dengan Pemeliharaan Digembalakan/ Angon dan Hubungannya dengan Tingkat Adopsi Inovasi Teknologi. Seminar Nasional Teknologi Dan Veteriner. Bogor.

Wardle, D. A., D. R. Bardgett, J. N. Klironomos, H. S la, W. H. van der Putten, H. Diana, \& Wall. 2004. Ecological Linkages Between Aboveground and Belowground Biota. Science. 304:1628-1633.

Wurzinger, P., C. Platzer, C. Ludl, E. Kirda, \& C. Kruegelk. 2009. SWAP: Mitigating XSS Attacks using a Reverse Proxy. University of California, Santa Barbara.

Zinkhan, E. C. \& D. E. Mercer. 1997. An assessment of agroforestry systems in the southern USA. Agroforestry Systems. 35:303-321. 